\section{Consideraciones éticas respecto del "pasaporte" COVID-19}

\author{
Ethical considerations related to the COVID-19 \\ "passport"
}

\section{Señor Director:}

Actualmente está en discusión a nivel internacional la posibilidad de entregar un carné o pasaporte COVID-19 a aquellas personas que, por haberse recuperado de la enfermedad, estarían inmunes a una nueva infección ${ }^{1}$. Los poseedores de este pasaporte podrían eximirse de hacer cuarentena, pudiendo volver al trabajo, al colegio y a la vida diaria, como lo menciona un reciente artículo, lo que sería especialmente importante cuando todavía no existe vacuna o tratamiento específico ${ }^{1}$. No obstante, esta posibilidad abre una serie de interrogantes, por lo que nos parece conveniente ahondar en las consideraciones éticas relacionadas con la implementación de este pasaporte o certificado de inmunidad.

En primer lugar, la buena ética se funda en una evidencia científica sólida. Por lo tanto, es necesario conocer aspectos esenciales de la inmunidad adquirida luego de la infección producida por el virus SARS-CoV-2, causante de la enfermedad COVID-19. Aún se desconoce la duración del período durante el cual un paciente puede eliminar el virus y seguir contagiando; asimismo, no se sabe si las personas pueden re-infectarse o cuánto dura la eventual inmunidad ${ }^{1,2}$. En este sentido, sería prematuro medir anticuerpos para determinar si una persona ha adquirido inmunidad, hasta que no se comprendan bien las características de la respuesta inmunológica a este virus ${ }^{2}$.

En segundo lugar, existe la posibilidad que aquellos que posean este pasaporte relajen las medidas de seguridad impuestas por la autoridad sanitaria, pudiendo así contagiar a terceros ${ }^{3}$. En esta misma línea, está la posibilidad que los exámenes empleados tengan falsos positivos que induzcan a los individuos a cambiar su comportamiento, siendo todavía susceptibles de ser infectados.

En tercer lugar, puede haber una población a la cual le resulte atractivo tener este carné, incurriendo de manera deliberada en conductas de riesgo para adquirir la enfermedad, para así poder participar de la vida social, civil y económica, especialmente si no están en condiciones de mantener ingresos durante los períodos de confinamiento" Esto puede exponerlos a riesgos a ellos y a sus contactos cercanos, especialmente si son población con menor acceso a atención de salud. Este carné podría contribuir a crear dos tipos de ciudadanos: los ya contagiados, que pueden tener más libertades, y un grupo de susceptibles, los que, paradójicamente, pueden ser los que más cumplieron con las medidas sanitarias para evitar el contagio.
Cuarto, podría contribuir a discriminar desde el punto de vista laboral a aquellos que tienen el carné, con lo que de alguna manera se beneficiarían los empleadores de este capital inmunológico que han adquirido sus trabajadores. Asimismo, estos pasaportes inmunitarios podrían aliviar las tareas que tienen los gobiernos de adoptar políticas que protejan los derechos económicos, de vivienda y de salud de toda la sociedad, al dar una solución rápida al tema del empleo en tiempos de confinamiento, como lo sugiere un reciente artículo de The Lancet ${ }^{1}$. En consecuencia, su uso podría aumentar la inequidad existente en la sociedad si es exigido para encontrar trabajo o para obtener cualquier otro privilegio 4 .

Quinto, este carné puede ser adulterado o transado en el mercado, si los gobiernos no dan garantías respecto de la seguridad del formato que se usará para entregarlo y quiénes tendrán acceso al testeo necesario para certificar la inmunidad. En países donde existe disparidad en el acceso a servicios de salud, presumiblemente sólo la población más aventajada tendrá facilidades para hacerse la prueba, por lo que su uso podría replicar las inequidades sanitarias ya existentes ${ }^{1,4}$. En consecuencia, en la eventualidad que se implemente, el costo de las pruebas requeridas para certificar la inmunidad debe ser financiado por el sistema de salud o los empleadores, pero no por los trabajadores ${ }^{4}$.

Sexto, cuando se reanuden los viajes internacionales, los países pueden considerar como requisito de ingreso el tener evidencia de inmunidad para el SARS-CoV-2, ya sea adquirida a través de vacunas o por contagios previos. Esto solo sería aconsejable de implementar si se conoce con exactitud las características de la respuesta inmune al virus, pero requiere diferenciar lo que es inmunidad mediada por vacunas (como el requisito de estar vacunado contra la fiebre amarilla que exigen ciertos países), que hacerlo mediante un carné COVID-19 adquirido luego de haber presentado la enfermedad, puesto que esto último podría estimular conductas de riesgo en la población interesada en viajar ${ }^{1}$.

Aunque no son los únicos argumentos en contra del uso de este pasaporte inmunitario, recomendamos no implementarlo hasta que el descubrimiento de una vacuna en contra de este virus pueda permitir acceso universal a adquirir inmunidad. Hasta que no se desarrolle inmunidad mediada por vacunas, la contribución que tendría el uso de estos pasaportes inmunitarios para la fuerza productiva de un determinado país sería limitada y su uso puede producir más daños que beneficios 5 .

Sofia P. Salas ${ }^{1}$

${ }^{\prime}$ Centro de Bioética, Facultad de Medicina. Clínica Alemana Universidad del Desarrollo. Santiago, Chile. 


\section{Referencias bibliográficas}

1.- Phelan A L. COVID-19 immunity passports and vaccination certificates: scientific, equitable, and legal challenges. The Lancet. Publicado en línea mayo 4, 2020. doi:https://doi. org/10.1016/S0140-6736(20)31034-5. Fecha de acceso: 12 de mayo de 2020.

2.- Kirkcaldy R D, King B A, Brooks J T. COVID-19 and postinfection immunity: limited evidence, many remaining questions. JAMA. Publicado en línea mayo 11, 2020. doi:10.1001/jama.2020.7869. Fecha de acceso: 11 de mayo de 2020.

3.- WHO. "Immunity passports" in the context of COVID-19. Scientific brief. Abril 24, 2020. Disponible en https://www. who.int/publications-detail/immunity- passports-in-thecontext-of-covid-19. Fecha de acceso 11 mayo 2020.
4.- Voo T C, Clapham H, Clarence C T. Ethical implementation of 'immunity passports' during the COVID-19 Pandemic. 8 abril 2020. Disponible en http://dx.doi.org/10.2139/ ssrn.3571830. Fecha de acceso: 12 de mayo de 2020.

5.- Fraser B. Chile plans controversial COVID-19 certificates. The Lancet 2020; 395 (10235):1473. Disponible en https://www.thelancet.com/action/showPdf?pii $=$ S0140-6736\%2820\%2931096-5. Fecha de acceso: 12 de mayo de 2020.

No hubo financiamiento. Conflicto de intereses: ninguno que declarar.

Correspondencia a: Sofía P. Salas. sofiasalas@udd.cl 